\title{
Development of Colletotrichum gloeosporioides Restriction Enzyme- Mediated Integration Mutants as Biocontrol Agents Against Anthracnose Disease in Avocado Fruits
}

\author{
N. Yakoby, R. Zhou, I. Kobiler, A. Dinoor, and D. Prusky
}

First, second, third, and fifth authors: Department of Postharvest Science of Fresh Produce, Agricultural Research Organization, The Volcani Center, Bet Dagan 50250; and first and fourth authors: Department of Plant Pathology and Microbiology, Hebrew University of Jerusalem, Faculty of Agricultural, Food and Environmental Quality Sciences, Rehovot 76100 Israel.

Current address of R. Zhou: Department of Natural Resource Sciences and Landscape Architecture, University of Maryland, College Park 20742.

Accepted for publication 30 October 2000.

\begin{abstract}
Yakoby, N., Zhou, R., Kobiler, I., Dinoor, A., and Prusky, D. 2001. Development of Colletotrichum gloeosporioides restriction enzymemediated integration mutants as biocontrol agents against anthracnose disease in avocado fruits. Phytopathology 91:143-148.

Reduced-pathogenicity mutants of the avocado fruit pathogen Colletotrichum gloeosporioides isolate Cg-14 (teleomorph: Glomerella cingulata) were generated by insertional mutagenesis by restriction enzymemediated integration (REMI) transformation. Following seven transformations, 3,500 hygromycin-resistant isolates were subjected to a virulence assay by inoculation on mesocarp and pericarp of cv. Fuerte avocado fruits. Fourteen isolates showed a reduced degree of virulence relative

the fruit's pericarp and mesocarp. Isolate Cg-M-1150 did not produce appressoria; it caused much reduced maceration on the mesocarp and no symptoms on the pericarp. Southern blot analysis of Cg-M-142 and Cg-M-1150 showed REMI at different XbaI sites of the fungal genome. Pre-inoculation of avocado fruit with Cg-M-142 delayed symptom development by the wild-type isolate. Induced resistance was accompanied by an increase in the levels of preformed antifungal diene, from 760 to $1,200 \mu \mathrm{g} / \mathrm{g}$ fresh weight 9 days after inoculation, whereas pre-inoculation with Cg-M-1150 did not affect the level of antifungal diene, nor did it delay the appearance of decay symptoms. The results presented here show that reduced-pathogenicity isolates can be used for the biological control of anthracnose caused by $C$. gloeosporioides attack.
\end{abstract} compared with wild-type Cg-14. Two isolates, Cg-M-142 and Cg-M-1150, were further characterized. $\mathrm{Cg}-\mathrm{M}-142$ produced appressoria on avocado pericarp similar to $\mathrm{Cg}-14$, but caused reduced symptom development on
Additional keywords: pathogen-fruit interaction, pathogenicity factors, postharvest decay.
Colletotrichum gloeosporioides (Penz.) Penz. \& Sacc. (teleomorph: Glomerella cingulata) is an important postharvest fungal pathogen attacking a wide variety of tropical and subtropical fruits $(7,22)$. C. gloeosporioides spores germinate on avocado fruits in the orchard by growing a germ tube that develops an appressorium (3). The appressorium produces infection hyphae that remain quiescent in the cells of the fruit's epidermal layer until the fruit ripens and softens during storage (20). The importance of Colletotrichum spp. as a worldwide economic problem and the search for biological means to control quiescent infection have led to the development of tools to control decay.

The search for biocontrol strategies against fruit and vegetable diseases after harvest has intensified in recent years, particularly with the banning of several pesticides (32). Most biocontrol strategies are directed toward wound pathogens and involve the use of antagonist bacterial strains that produce antibiotics, compete successfully for nutrients, or produce lytic enzymes that affect germinating fungal hyphae by possible direct degradation of cell wall-degrading enzymes or direct action against the pathogen's hyphae $(6,8,9,32,33)$. The search for biocontrol agents against pathogens causing quiescent infections has been more difficult because the infecting hyphae are protected from microorganisms once the pathogen has penetrated the plant cuticle. Thus, few reports

Corresponding author: D. Prusky; E-mail address: prusky33@netvision.net.il

Publication no. P-2000-1218-01R

(c) 2001 The American Phytopathological Society describe the presence of naturally occurring strains for biological control of quiescent infections in general and in avocado in particular $(12,14,16)$. In the absence of a potentially direct interaction between the antagonist and quiescent-infecting pathogens, and the need to understand the nature of the genetic alteration accrued in the used strain, it was justified to developed reduced-pathogenicity mutants of $C$. gloeosporioides, isolated from avocado fruit, which induce resistance to anthracnose, as an approach to controlling quiescent Colletotrichum infections.

In Colletotrichum spp., transformation-mediated genetic manipulation was established to enable heterologous gene expression (34), targeted gene disruption (5), and random gene disruption by restriction enzyme-mediated integration (REMI) (25). REMI involves the transformation of an organism with a linear fragment of DNA in the presence of the restriction enzyme used to linearize the fragment (19). Under these conditions, the linear DNA integrates into the chromosome at the restriction sites recognized by that particular enzyme $(13,18,28)$. REMI was first used in yeast (28) to study the mechanism of illegitimate recombination. REMI protocols were adjusted to other systems, facilitating increased transformation-mediated gene disruption in Dictyostelium discoideum (18), Cochliobolus heterostrophus (35), Magnaporthe grisea (29), Ustilago maydis (4), Alternaria alternata (1), Colletotrichum spp. (25), and Penicillium paxilli (11).

We describe the development of reduced virulence mutants generated by REMI and their use to elevate the natural resistance mechanism of avocado fruit, as a way of reducing the severity of anthracnose during storage. 


\section{MATERIALS AND METHODS}

Avocado fruits, fungal isolates, and growth media. Avocado fruits (Persea americana Miller var. drymifolia (Schidl. and Cham.) S. F. Blake cv. Fuerte) were obtained from K. G. Brenner, Israel. A single-spore isolate of $C$. gloeosporioides, $\mathrm{Cg}$-14, was obtained from a decayed avocado fruit (cv. Fuerte), and spores were maintained in 10-mM sodium-phosphate buffer ( $\mathrm{pH} 7.2)$, $40 \%$ glycerol at $-80^{\circ} \mathrm{C}$. Three-week-old conidia were harvested from Mathur's medium $\left(\mathrm{M}_{3} \mathrm{~S}\right)$ plates (30) and used for culture and fruit inoculation. Spore production was estimated on 3-week-old colonies on $\mathrm{M}_{3} \mathrm{~S}$ plates at $20^{\circ} \mathrm{C}$ by spore-counting with a hemacytometer (Brand, Wertheim, Germany).

Vector construction, fungal transformation, and isolate selection. The $h p h-B$ cassette (hygromycin phosphotransferase), conferring resistance to hygromycin, was subcloned from pHA-1.3 (25) by restriction with HindIII and XbaI (Promega, Madison, WI), generating a 2.13-kb fragment that was ligated into pGEM-7Z (Promega), restricted with the same enzymes. The product, pGH-1 $(5.13 \mathrm{~kb})$, was used as a transformation vector. For transformation, 4-day-old mycelia were harvested and $3 \mathrm{~g}$ were digested with Novozyme 234 (Calbiochem-Novabiochem Corp., La Jolla, CA) and $\beta$-glucuronidase (Sigma Chemical, St. Louis) to obtain fungal protoplasts that were transformed with pGH-1 $(1 \mu \mathrm{g})$ in the presence of 24 units of XbaI-restriction enzyme, as initially described by Redman and Rodriguez (25). The transformation suspension was incubated for $48 \mathrm{~h}$ at $22^{\circ} \mathrm{C}$ and selected on media containing $100 \mu \mathrm{g} / \mathrm{ml}$ of hygromycin (25). Hygromycin-resistant colonies were collected 4 to 8 days later and transferred to new hygromycin plates. Colonies were transferred to $\mathrm{M}_{3} \mathrm{~S}$ plates to enhance sporulation, and a single-spore culture was obtained. The mutants were sporulated by transferring the colonies to $\mathrm{M}_{3} \mathrm{~S}$ media plates, and in order to test transformation stability, spores were transferred back to hygromycin plates.

Hygromycin-resistant colonies were tested for their ability to induce symptoms on the pericarp and maceration of the mesocarp of peeled fruits. A single freshly harvested fruit was spot inoculated on both sides of its longitudinal axis. Each fruit was inoculated at three points with $C$. gloeosporioides isolate $\mathrm{Cg}-14$ and at three points with the transformed isolate. Inoculation was carried out on the pericarp and mesocarp (after peeling a 1- to 2-mm

TABLE 1. Phenotypic analysis of Colletotrichum gloeosporioides restriction enzyme-mediated integration

\begin{tabular}{lclccc}
\hline Isolate & $\begin{array}{c}\text { Growth } \\
\text { on } \mathrm{M}_{3} \mathrm{~S}^{\mathrm{a}}\end{array}$ & $\begin{array}{c}\text { Sporulation } \\
\text { in vitro }^{\mathrm{b}}\end{array}$ & $\begin{array}{c}\text { Pericarp } \\
\text { attack }^{\mathrm{c}}\end{array}$ & $\begin{array}{c}\text { Mesocarp } \\
\text { attack }^{\mathrm{c}}\end{array}$ & $\begin{array}{c}\text { Autotroph } \\
\text { growth }^{\mathrm{d}}\end{array}$ \\
\hline Cg-M-6 & Well & Normal & 4 & 1 & + \\
Cg-M-25 & Well & Normal & 4 & 2 & + \\
Cg-M-104 & Well & Normal & 3 & 1 & - \\
Cg-M-114 & Well & Normal & 3 & 2 & + \\
Cg-M-142 & Well & Enhanced & 3 & 2 & + \\
Cg-M-154 & Well & Normal & 3 & 2 & + \\
Cg-M-182 & Slow & Very low & 4 & 3 & - \\
Cg-M-392 & Well & Normal & 3 & 1 & + \\
Cg-M-627 & Slow & Very low & 4 & 3 & + \\
Cg-M-807 & Well & Normal & 3 & 1 & + \\
Cg-M-809 & Slow & Very low & 4 & 3 & - \\
Cg-M-1150 & Well & Low & 4 & 3 & + \\
Cg-M-1210 & Well & Normal & 3 & 1 & - \\
Cg-M-1230 & Well & Normal & 2 & 1 & + \\
\hline
\end{tabular}

a Growth on Mathur's medium $\left(\mathrm{M}_{3} \mathrm{~S}\right)$ was compared with that of $\mathrm{Cg}-14$ : well = similar growth; and slow = reduced growth .

b Sporulation was estimated by spore counting relative to $\mathrm{Cg}$-14: enhanced = more spores; low = less spores; normal = the same amount; and very low = just a few spores.

c Decay development on mesocarp and pericarp was estimated with the following scale: $1=0$ to $9 \%$ reduction; $2=10$ to $50 \%$ reduction; $3=51$ to $90 \%$ reduction; and $4=>90 \%$ reduction.

${ }^{\mathrm{d}}$ Colonies were grown on minimal media for auxotrophic $(-)$ or autotrophic (+) growth detection. thickness of pericarp) by placing a $3-\mathrm{mm}^{2}$ disk of media taken from the edge of a 4-day-old colony on hygromycin plates and from hygromycin without supplemented hygromycin for $\mathrm{Cg}-14$. Mesocarp maceration ( 2 to $3 \mathrm{~mm}$ deep, dark spots) occurred within $48 \mathrm{~h}$, and pericarp symptoms occurred (darkening) within 10 to 12 days at $22^{\circ} \mathrm{C}$. The diameters (millimeters) of the decay and maceration caused by the transformed isolates and $\mathrm{Cg}-14$ were compared. Colonies that showed a lack of, or reduced, macerating abilities were re-inoculated on 20 fruits for further analysis (described previously).
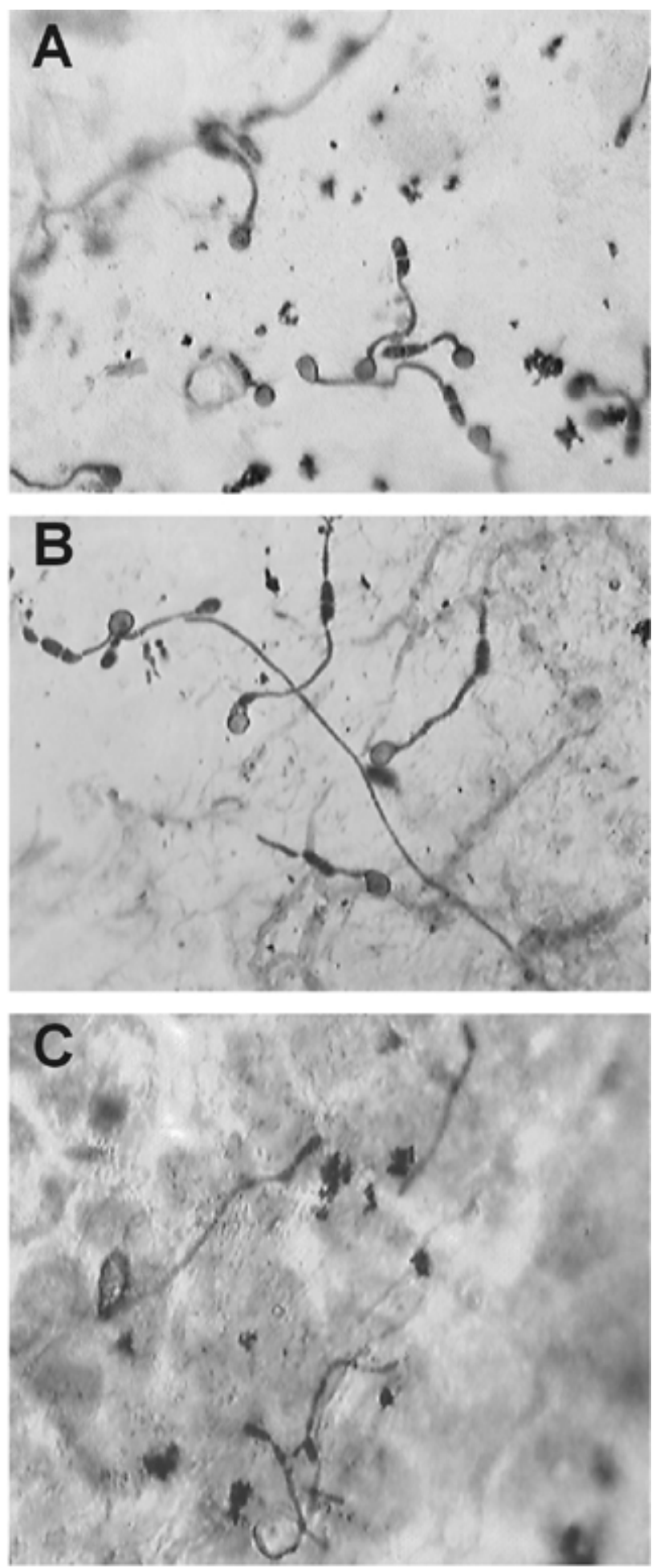

Fig. 1. Spore germination and appressorium formation by Colletotrichum gloeosporioides isolates $48 \mathrm{~h}$ after cv. Fuerte avocado fruit pericarp inoculation with A, Cg-14; B, Cg-M-142; and C, Cg-M-1150. 
Fruit protection assays and phenotypic characterization of transformed isolates. Fruit protection assays were carried out by dipping 20 freshly harvested avocado fruits for $30 \mathrm{~s}$ in a spore suspension $\left(5 \times 10^{5}\right.$ spores per ml) of Cg-M-142 or Cg-M-1150 and storing for $24 \mathrm{~h}$ at $90 \%$ relative humidity $(\mathrm{RH}), 20^{\circ} \mathrm{C}$. Fruits were then inoculated with $10 \mu \mathrm{l}$ of $\mathrm{Cg}-14$ spore suspension $(1 \times$ $10^{6}$ spores per $\mathrm{ml}$ ) at six points, three on each side of the longitudinal axis of the fruit, and incubated at $22^{\circ} \mathrm{C}$ in $90 \% \mathrm{RH}$ for 15 days. Isolates were characterized for appressorium formation by spot inoculation of the different isolate spores $\left(1 \times 10^{6}\right.$ spores per $\mathrm{ml}$ ) on the fruit's pericarp and 48-h later were observed under a light microscope (BH-2; Olympus, Tokyo, Japan) after cutting a 0.5-mm-deep slice of the inoculated pericarp with a scalpel. Appressorium formation was photographed by video camera (APPLITEC MSV-800; Azor, Israel). Isolate growth rates were measured on three replicates of $\mathrm{M}_{3} \mathrm{~S}$ plates or five replicates of the pericarp by inoculation with $10 \mu \mathrm{l}$ of spore suspension as described previously. Growth rate on the mesocarp was measured by inoculating at six points with a $3-\mathrm{mm}^{2}$ square of media with growing isolate (described previously). All experiments were repeated at least three times over two consecutive avocado seasons.

Southern blot analysis and plasmid rescue. Fungal DNA was obtained from $0.2 \mathrm{~g}$ of lyophilized hyphae as described by Rodriguez (26). Fungal DNA (5 $\mu$ g) was restricted for $15 \mathrm{~h}$ at $37^{\circ} \mathrm{C}$ by 20 units of HindIII or XbaI. Restricted DNA was run on a $0.8 \%$ agarose gel for $15 \mathrm{~h}$ and blotted onto $\mathrm{HyBond}^{+}$nylon membrane (Amersham, Buckinghamshire, U.K.) according to the capillary method (27).

All hybridizations were carried out at $65^{\circ} \mathrm{C}$, and washes were with $0.1 \times$ sodium chloride/sodium citrate. The membrane was probed with either a 4.1-kb pel gene (GenBank Accession No. AF052632) or pGH-1. The blotted membrane was exposed to both X-ray film and Fuji BAS sample screen, and the image was captured with the Fuji BAS reader (Fujifilm, Tokyo, Japan). Bands were quantified by MacBAS software (version 2.3, Fujifilm).

For plasmid rescue, $1 \mu \mathrm{g}$ of fungal DNA was used. DNA was restricted with 10 units of XbaI or HindIII for $15 \mathrm{~h}$. Restriction enzymes were separated from the DNA with phenol/chloroform (50:50, vol/vol) followed by ethanol precipitation. The DNA was eluted and subjected to ligation using ligase (Promega) for $12 \mathrm{~h}$ at $4{ }^{\circ} \mathrm{C}$. Ligation mixture from each isolate $(1 \mu \mathrm{l})$ was electroporated, using Gene Pulser II (Bio-Rad Laboratories, Hercules, CA), into delayed-hypersensitivity $5 \alpha$-competent cells (prepared according to Bio-Rad Laboratories recommendations). Bacteria were grown on Luria-Bertani media (27) supplemented with $100 \mu \mathrm{g}$ of ampicillin per milliliter at $37^{\circ} \mathrm{C}$ for $15 \mathrm{~h}$. Randomly selected colonies were grown for plasmid minipreparation with Wizard Plus SV Minipreps (Promega). Plasmids were restricted with the same restriction enzyme used for their rescue and run on a $1 \%$ agar gel followed by ethidium bromide staining.

Antifungal diene extraction. A $10 \mathrm{-g}$ sample of avocado pericarp (1 to $2 \mathrm{~mm}$ thick) was homogenized in $95 \%$ ethanol in an Omni-Mixer (Sorvall, DuPont Company, Newtown, CT) at full speed for $3 \mathrm{~min}$. The ethanol extract was dried in a rotary evaporator at $40^{\circ} \mathrm{C}$, redissolved in $10 \mathrm{ml}$ of distilled water, and the organic phase was extracted by fractionation with dichloromethane. Following two extractions, the organic phases were pooled, dried with anhydrous $\mathrm{MgSO}_{4}$ (Riedel-deHaen, Seelze, Germany), and evaporated to dryness. Samples were redissolved in $1 \mathrm{ml}$ of ethanol AR (Bio Lab, Jerusalem, Israel) and analyzed by high performance liquid chromatography (23). The average values of three separate extractions are presented. The experiment was repeated twice during each year of two consecutive avocado seasons.

\section{RESULTS}

C. gloeosporioides reduced-pathogenicity mutants. A transformation vector was constructed by subcloning the $h p h-B$ gene into pGEM-7Z, generating pGH-1 with two unique restriction sites, $X b a \mathrm{I}$ and HindIII. Transformation of pGH-1 into the fungal protoplasts as REMI (in the presence of 24 units of $\mathrm{XbaI}$ ) elevated the recovered colonies from approximately 50 obtained using native supercoiled DNA to 500 per microgram of plasmid DNA. Following seven transformations, 3,500 recovered colonies were selected on hygromycin and used to inoculate avocado mesocarp and pericarp. Fourteen isolates showed varying levels of symptom development on avocado fruit, and four isolates exhibited auxotrophic growth on minimal media (Table 1).

Two isolates, Cg-M-142 and Cg-M-1150, showed no spore morphological difference to $\mathrm{Cg}-14$, but demonstrated reduced
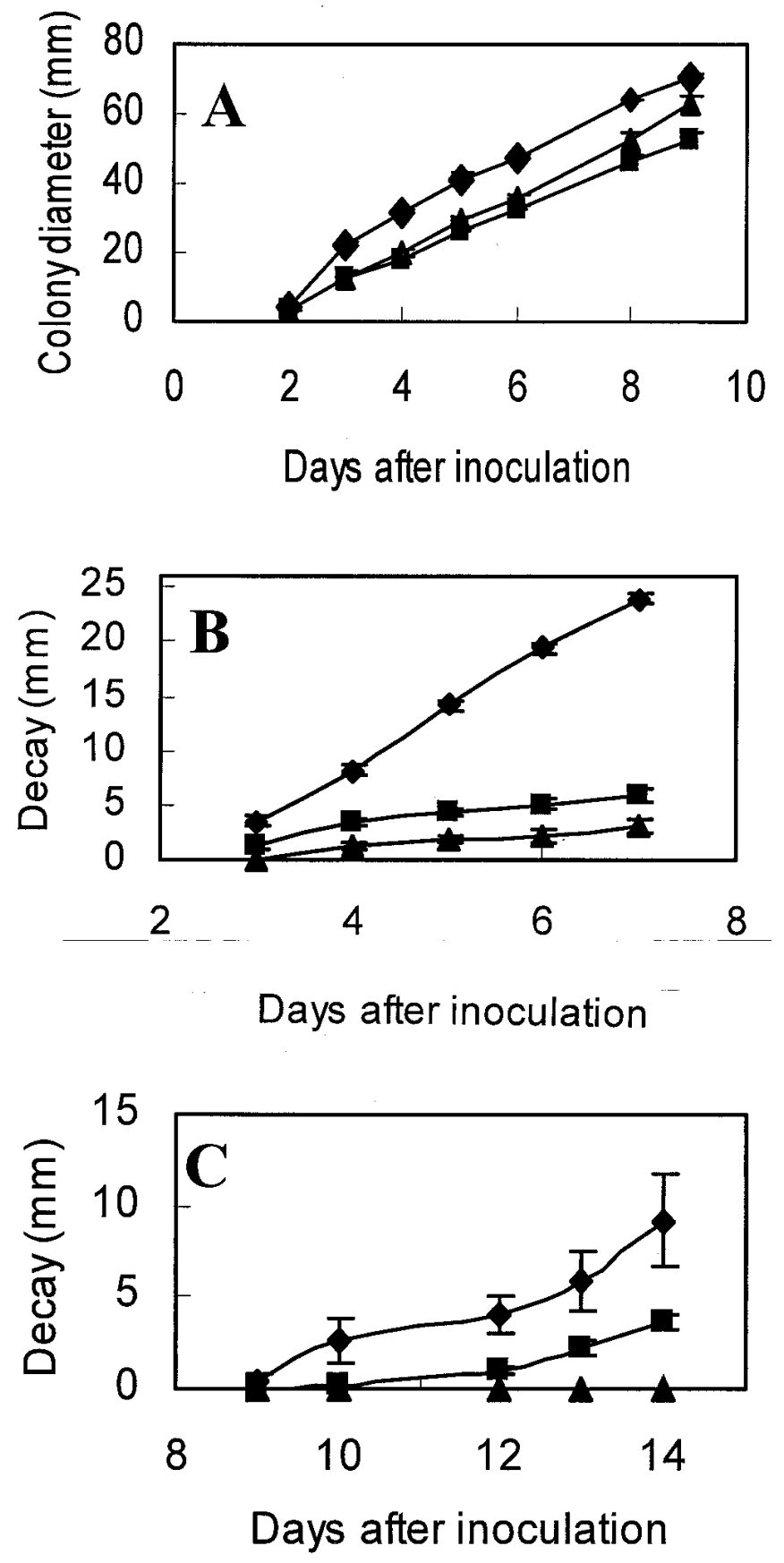

Fig. 2. A, Growth rate in vitro on Mathur's medium plates and $\mathbf{B}$, in vivo decay development on pericarp or $\mathbf{C}$, mesocarp of avocado fruits (cv. Fuerte) by Colletotrichum gloeosporioides isolates $\mathrm{Cg}-14, \mathrm{Cg}-\mathrm{M} 142$, and $\mathrm{Cg}-\mathrm{M}-1150$. Experiments were repeated three times over two consecutive harvesting seasons. Standard errors of the means are shown as bars on data points; differences between means were analyzed by analysis of variance and are significantly different $(P<0.01)$. 
virulence on avocado fruits. Three-week-old colonies of isolate Cg-M-142 sporulated (approximately $1 \times 10^{7}$ spores per $\mathrm{cm}^{2}$ ) approximately 10 -fold more than $\mathrm{Cg}-14$, whereas isolate $\mathrm{Cg}-\mathrm{M}-1150$ showed (approximately $1 \times 10^{5}$ spores per $\mathrm{cm}^{2}$ ) an approximate 10 -fold reduction in spore production. Isolates $\mathrm{Cg}-14, \mathrm{Cg}-\mathrm{M}-142$, and $\mathrm{Cg}-\mathrm{M}-1150$ generated similar germination tubes on the pericarp (Fig. 1A, B, and C, respectively) after 48 h; however, only Cg-14 and Cg-M-142 formed 100\% appressoria (Fig. 1A and $\mathrm{B}$, respectively). Isolate $\mathrm{Cg}-14$ formed $60 \%$ of its appressoria within $24 \mathrm{~h}$, whereas isolate Cg-M-142 showed delayed appressorium formation during that timeframe. No significant differences on the size, pigmentation, and wall thickness of appressoria between Cg-14 and Cg-M-142 were observed. Isolate Cg-M-1150 generated no appressoria at all.

Growth on $\mathrm{M}_{3} \mathrm{~S}$ plates was similar for all three isolates (Fig. 2A). However, isolate $\mathrm{Cg}-14$ was the fastest growing on the fruit mesocarp and pericarp (Fig. 2B and C). Isolate Cg-M-1150 was growth-retarded on fruit, especially on the pericarp where no decay symptoms developed (Fig. 2C). Isolate Cg-M-142 showed statistically significant reduced virulence relative to $\mathrm{Cg}$-14 but enhanced virulence relative to $\mathrm{Cg}-\mathrm{M}-1150$ (Fig. 2B and C).

Molecular characterization of the two REMI mutants. Southern blot analysis using either pGH-1 (Fig. 3A) or the 4.1-kb pel gene (Fig. 3B) showed Cg-M-142 and Cg-M-1150 REMI as a band at $5.13 \mathrm{~kb}$, the size of pGH-1, when restricted with $\mathrm{XbaI}$; isolate Cg-M-1150 showed additional ectopic integration as a band at $5.5 \mathrm{~kb}$ (Fig. 3A). This was confirmed by running HindIIIrestricted DNA of $\mathrm{Cg}-\mathrm{M}-1150$, which revealed the same $5.13-\mathrm{kb}$ band and an additional three bands representing the ectopic integration and the two end plasmids with the flanking fungal DNA (Fig. 3A). Isolate Cg-M-142 restricted with HindIII produced three bands: two bands at 4.5 and $6.0 \mathrm{~kb}$, consisting of the integrated plasmids with a genomic flanking region, and a stronger band at $4.3 \mathrm{~kb}$, representing the two $h p h-B$ cassettes (Fig. 3A). Isolate $\mathrm{Cg}-14$ did not hybridize at all with the pGH-1. The membrane was probed with the single-copy $4.1-\mathrm{kb}$ pel to show that the strong bands appearing at $5.13 \mathrm{~kb}$ were a result of the integration of 10 plasmids in tandem sequence for $\mathrm{Cg}-\mathrm{M}-1150$, two in tandem sequence for Cg-M-142 (Fig. 3B), and not due to different amounts of loaded DNA that was quantified with MacBAS software.

Plasmid rescue from genomic DNA of isolate Cg-M-142 restricted with $\mathrm{XbaI}$ (p142X4) and of isolate Cg-M-1150 restricted with XbaI (p1150X1) or HindIII (p1150H1) showed the 5.13-kb pGH-1-band size for both isolates (Fig. 4), further supporting XbaI REMI in both isolates. The HindIII-rescued plasmid from Cg-M-142 (p142H1 and p142H3), generating the two upper bands appearing on the Southern blot at 6.0 and $4.5 \mathrm{~kb}$, consisted of a $5.13-\mathrm{kb}$ transformation vector and $0.87 \mathrm{~kb}$ of fungal genome flanking area for the former, and the 3.0-kb pGEM-7Z and $1.5 \mathrm{~kb}$ of fungal genome flanking area for the latter (Fig. 3A). The 4.3-kb band was not rescued because it consisted of two head-to-head $h p h-B$ cassettes with no pGEM-7Z. The 5.5-kb band, detected when Cg-M-1150 DNA was restricted with XbaI (Fig. 3A), did not appear when the membrane was probed with pGEM-7Z (data not shown), supporting the band's consisting of $h p h-B$ with no

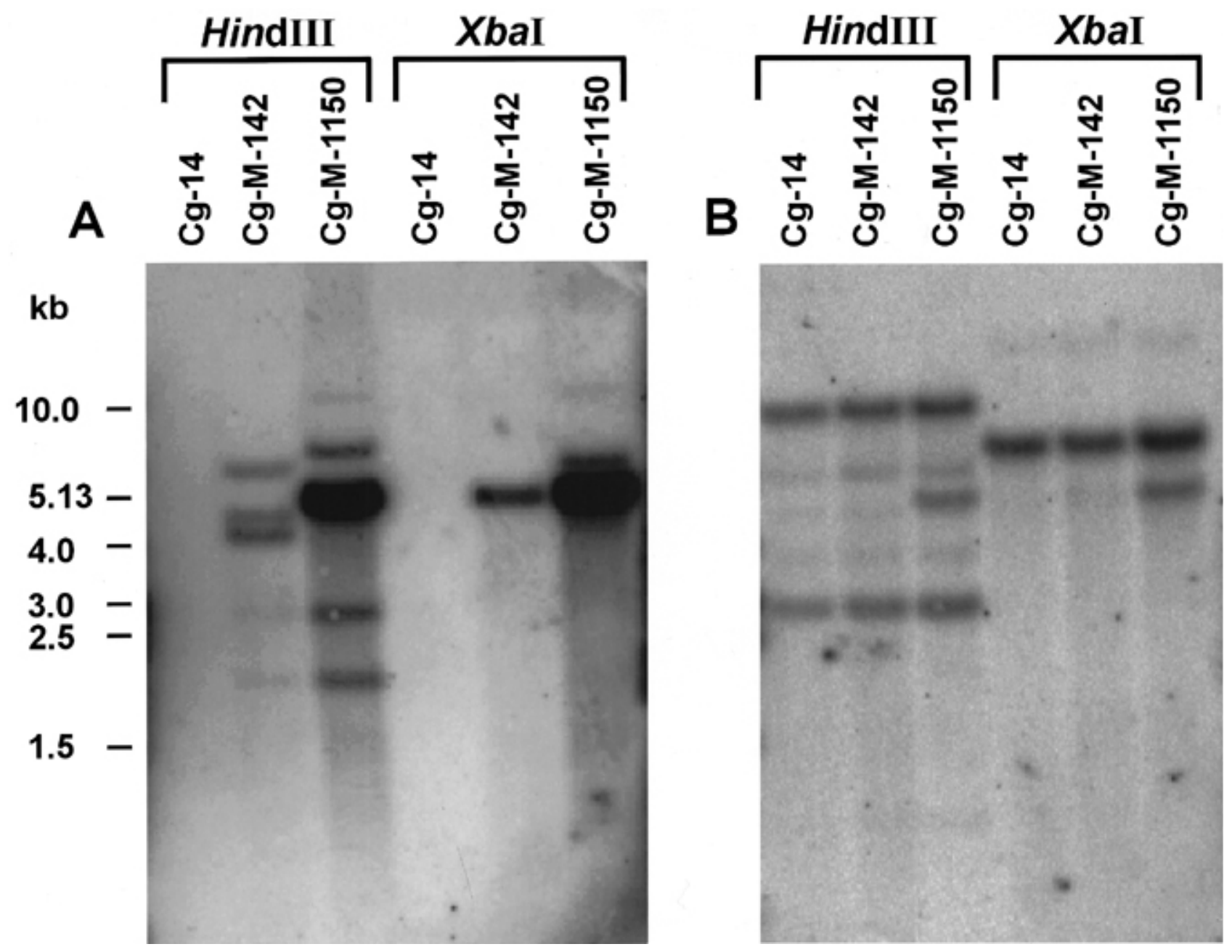

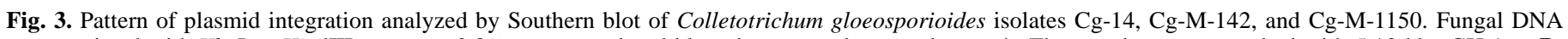

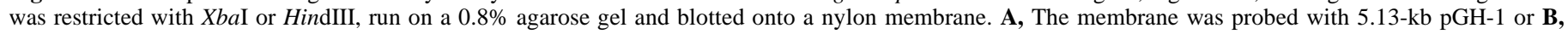
4.1-kb pel, and exposed to Fuji BAS sample screen. 
vector. Sequence analysis of the genomic DNA from the flanking area of Cg-M-142 showed no homology to any known sequences in GenBank.

Fruit protection by pre-inoculation with REMI mutants. Avocado fruits pre-inoculated with a spore suspension of $\mathrm{Cg}-\mathrm{M}$ 142 before spot inoculation with the wild-type Cg-14 exhibited significantly reduced decay development (Fig. 5). However, preinoculation with Cg-M-1150 followed by spot inoculation with the wild-type $\mathrm{Cg}-14$ did not affect decay development (data not shown). Freshly harvested avocado fruits inoculated with Cg-M142 exhibited an increased level of antifungal diene 9 days later, from $767 \pm 97 \mu \mathrm{g} / \mathrm{g}$ fresh weight in noninoculated fruits to $1,189 \pm$ $139 \mu \mathrm{g} / \mathrm{g}$ fresh weight. However, fruit inoculated with Cg-M-1150 showed no increase in diene level or elevation in fruit resistance to $\mathrm{Cg}-14$. Results are the average values of three independent extractions with their standard error.

\section{DISCUSSION}

As a mutation tool to generate biocontrol agents, REMI generated $0.4 \%$ C. gloeosporioides mutants, compared with $2.0 \%$ for $C$. magna (24), $1.4 \%$ for $U$. maydis (4), and $0.27 \%$ in D. discoideum (18). Following REMI transformation, the integration of linear DNA molecules into the genome can be either ectopic or restricted-enzyme mediated (into the restriction site generated by the specific restriction enzyme), as one copy or in tandem copies. We found tandem integration of the plasmid in 2 and 10 copies, as reported for $U$. maydis $(10,17,31)$. Unlike other methods of generating random mutations in fungi, where the mutated gene remains an enigma, REMI enables molecular characterization of the isolate in order to find the genotypic cause for the phenotype. Isolate Cg-M-142 yielded three bands when probed with pGH-1 (Fig. $3 \mathrm{~A}$ ); two of these bands were retrieved by plasmid rescue but the low molecular weight band was not. Furthermore, when probed with $h p h-B$ the two upper bands did not appear (data not shown). These data suggest that Cg-M-142 has head-to-head, two-plasmid REMI (one band when restricted with $X b a \mathrm{I}$ ), where the two top bands are pGEM with flanking regions and the lower band represent the two $h p h-B$ cassettes. Isolate $\mathrm{Cg}-\mathrm{M}-1150$ yielded two bands when probed with pGH-1. The upper band did not appear when the membrane was probed with pGEM (data not shown), suggesting it to be the $h p h-B$ cassette in ectopic integration. The main band appearing in both XbaI- and HindIII-restricted Cg-M$1150 \mathrm{DNA}$ at $5.13 \mathrm{~kb}$ suggests head-to-tail tandem integration of pGH-1. This was further confirmed by plasmid rescue, which

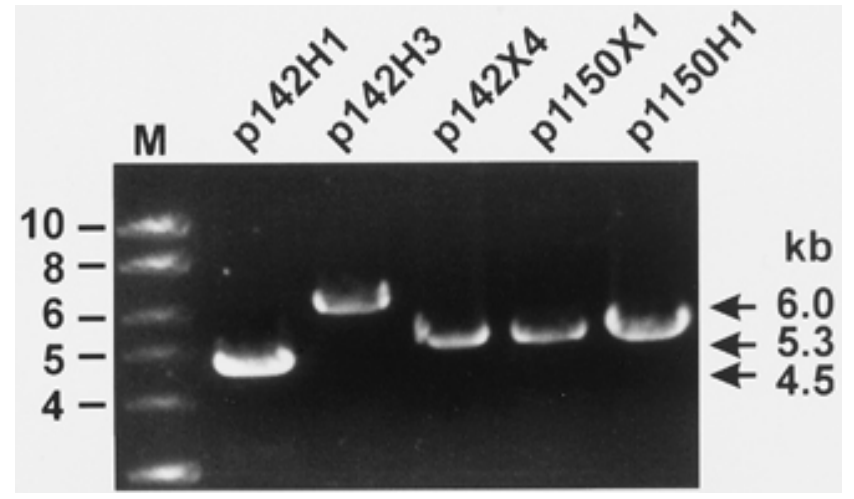

Fig. 4. Plasmid rescue analysis of Colletotrichum gloeosporioides isolates Cg-M-142 and Cg-M-1150 restricted with HindIII (H) and XbaI (X). Fungal DNA was restricted with XbaI or HindIII and subjected to ligation. One microliter of the ligation mixture of each isolate was electroporated into delayed-hypersensitivity $5 \alpha$-competent cells. Colonies were selected (last number on plasmid name) on Luria-Bertani media supplemented with $100 \mu \mathrm{g} / \mathrm{ml}$ of ampicillin. Randomly selected colonies were grown for plasmid minipreparation. Plasmids (p) were restricted with the same restriction enzyme used for their rescue and run on a $1 \%$ agarose gel. retrieved pGH-1 when the plasmid was XbaI- and HindIII-rescued. The ability to rescue plasmids can supply information as to what genes are important for direct (pathogenicity factors) or indirect (regulatory genes) fungal attack, as has been demonstrated with other fungi (19). We are currently working on a genotypic characterization of the putative-disrupted genes in order to link them to the phenotypic appearance of the different isolates.

The development of biocontrol agents against quiescent pathogens has been unsuccessful because of the lack of a direct interaction between the biocontrol agent and the pathogen. Thus, there are few reports describing the biological control of quiescent infections $(12,14,16)$. Korsten et al. (15) used protective spray treatments with Bacillus subtilis against avocado anthracnose disease caused by $C$. gloeosporioides. For effective control, continuous protective sprays are necessary because fruits are continually spore-infested in the orchard (15).

Postharvest treatment of avocado fruits with the reduced-pathogenicity strain Cg-M-142 increased their antifungal diene level and enhanced their resistance to $\mathrm{Cg}-14$ attack. Prusky et al. (21) reported that pre-inoculation of avocado fruits with $\mathrm{Cg}$ - 14 stimulates the host for a short time only, and thus, does not increase diene level or fruit resistance, whereas the higher level of diene induced by $\mathrm{Cg}-\mathrm{M}-142$ is proposed to occur because of a vigorous stimulation of the host-antifungal compound, as seen 9 days after inoculation. This hypothesis is based on postharvest inoculation treatment of avocado fruits with a nonpathogenic mutant (path-1) of C. magna that shows minor symptoms on mature avocado fruit, enabling an increase in the level of antifungal diene, concomitantenhanced resistance to $C$. gloeosporioides attack (21). The inability of $\mathrm{Cg}-\mathrm{M}-1150$ to increase fruit resistance with no symptom development on the pericarp cannot be explained by the $15 \%$ reduction in growth on $\mathrm{M}_{3} \mathrm{~S}$ media. The lack of appressorium formation with no symptom development on the fruit by $\mathrm{Cg}-\mathrm{M}-1150$ and no increase in the antifungal diene level may further support the importance of appressorium formation as the initial stage to breaching the wax and the establishment of early interaction between the fungus and the fruit, as suggested by Beno-Moualem and Prusky (2).

Sufficient duration and efficiency of the defense induction of Colletotrichum strains is mandatory to prevent termination of the quiescent period in wild-type $C$. gloeosporioides. The use of a

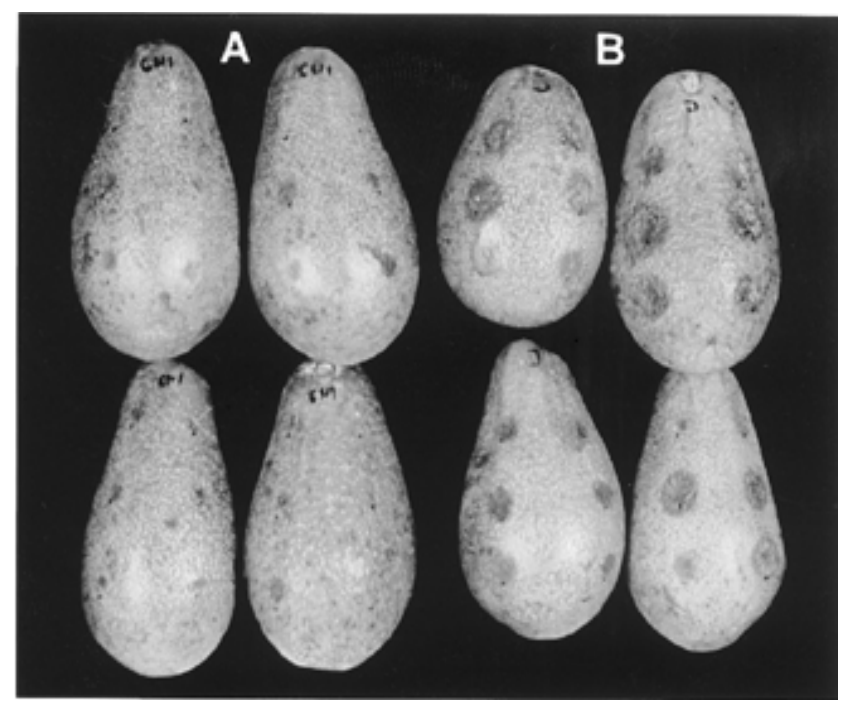

Fig. 5. Decay development of Colletotrichum gloeosporioides isolate Cg-14 following preinoculation of $\mathrm{cv}$. Fuerte avocado fruit with A, reduced virulence mutant $\mathrm{Cg}-\mathrm{M}-142$, or $\mathbf{B}$, dipped in water as a control. Twenty freshly harvested fruit were dipped for $30 \mathrm{~s}$ in a spore suspension of Cg-M-142 or water as a control. Fruits were inoculated 24-h later at six points and incubated for 15 days, as described in text. Experiments were repeated three times during two consecutive harvesting seasons. 
REMI mutant to increase the natural resistance mechanism of avocado fruit demonstrates that this approach may be adopted to control decay in other postharvest pathosystems. Data presented here demonstrates that genetic manipulation can be used for the construction of a local biocontrol agent. Furthermore, the possibility of easily exploring the mutation by plasmid rescue could simplify the isolate's registration as a biocontrol agent.

\section{ACKNOWLEDGMENTS}

This research was supported by Research Grants IS-2686-96 to D. Prusky from The U.S.-Binational Agricultural Research and Development Fund, the German-Israel Agricultural Research Agreement for the Benefit of the Third World, and the U.S.-Israel Cooperative Development Research Program. N. Yakoby was granted personal scholarships from the Israel Fruit Marketing Board/Ministry of Agriculture and Rural Development and from The Association of Trustees and Friends of the Agricultural Research Organization in the name of "Avigad and his daughter Dovrat".

\section{LITERATURE CITED}

1. Akamatsu, H., Itoh, Y., Kodama, M., Otani, H., and Kohmoto, K. 1997. AAL-toxin-deficient mutants of Alternaria alternata tomato pathotype by restriction enzyme-mediated integration. Phytopathology 87:967-972.

2. Beno-Moualem, D., and Prusky, D. 2000. Early events during quiescent infection development by Colletotrichum gloeosporioides in unripe avocado fruits. Phytopathology 90:553-559.

3. Binyamini, N., and Schiffmann-Nadel, M. 1972. Latent infection in avocado fruit due to Colletotrichum gloeosporioides. Phytopathology 62:592-594.

4. Bolker, M., Bohnert, H. U., Braun, K. H., Gorl, J., and Kahmann, R. 1995. Tagging pathogenicity genes in Ustilago maydis by restriction enzyme-mediated integration (REMI). Mol. Gen. Genet. 248:547-552.

5. Bowen, K. J., Templeton, D. M., Sharrock, R. K., Crowhurst, R. N., and Rikkerink, H. A. R. 1995. Gene inactivation in plant pathogen Glomerella cingulata: three strategies for the disruption of the pectin lyase pnl A. Mol. Gen. Genet. 246:196-205.

6. Chalutz, E., and Wilson, C. L. 1990. Postharvest biocontrol of green and blue mold and sour rot of citrus fruit by Debaryomyces hansenii. Plant Dis. 74:134-137.

7. Coates, L. M., Muirhead, I. F., Irwin, J. A. G., and Gowanlock, D. 1993. Initial infection processes by Colletotrichum gloeosporioides on avocado fruit. Mycol. Res. 97:1363-1370.

8. Droby, S., Chalutz, E., Wilson, C. L., and Wisniewski, M. 1989. Characterization of the biocontrol activity of Debaryomyces hansenii in the control of Penicillium digitatum on grapefruit. Can. J. Microbiol. 35:794-800.

9. Elad, Y., and Kapat, A. 1999. The role of Trichoderma harzianum protease in the biocontrol of Botrytis cinerea. Eur. J. Plant Pathol. 105:177-189.

10. Fotheringham, S., and Hollman, W. K. 1989. Cloning and disruption of Ustilago maydis genes. Mol. Cell Biol. 9:4052-4055.

11. Itoh, Y., and Scott, B. 1997. Effect of dephosphorylation of linearized PAN-7-1 and of addition of restriction enzymes on plasmid integration in Penicillium paxilli. Curr. Genet. 32:147-151.

12. Jeffries, P., and Koomen, I. 1992. Strategies and prospects for biological control Colletotrichum. Pages 337-357 in: Colletotrichum: Biology, Pathology, and Control. J. A. Bailey and M. J. Jeger, eds. CAB International, Wallingford, U.K.

13. Kahmann, R., and Basse, C. 1999. REMI (restriction enzyme-mediated integration) and its impact on the isolation of pathogenicity genes in fungi attacking plants. Eur. J. Plant Pathol. 105:221-229.

14. Koomen, I., and Jeffries, P. 1993. Effect of antagonistic microorganisms on the post-harvest development of Colletotrichum gloeosporioides on mango. Plant Pathol. 42:230-237.

15. Korsten, L., De Villiers, E. E., Wehner, F. C., and Kotzé, J. M. 1997. Field sprays of Bacillus subtilis and fungicides for control of preharvest fruit diseases of avocado in South Africa. Plant Dis. 81:455-459.

16. Korsten, L., and Kotze, J. M. 1992. Postharvest biocontrol of avocado postharvest diseases. Proc. World Avocado Congr. 2:473-477.

17. Kronstad, J. W., Wang, J., Covert, S. F., Holden, D. W., McKnight, G. L., and Leong, S. A. 1989. Isolation of metabolic genes and demonstration of gene disruption in the phytopathogenic fungus Ustilago maydis. Gene 79:97-106

18. Kuspa, A., and Loomis, W. F. 1992. Tagging developmental genes in Dictyostelium by restriction enzyme-mediated integration of plasmid DNA. Proc. Natl. Acad. Sci. USA 89:8803-8807.

19. Maier, F. J., and Schäfer, W. 1999. Mutagenesis via insertional or restriction enzyme-mediated-integration (REMI) as a tool to tag pathogenicity related genes in plant pathogenic fungi. Biol. Chem. 380:855-864.

20. Prusky, D. 1996. Pathogen quiescence in postharvest diseases. Annu. Rev. Phytopathol. 34:413-434.

21. Prusky, D., Freeman, S., Rodriguez, R. J., and Keen, N. T. 1994. A nonpathogenic mutant of Colletotrichum magna induces resistance to $C$. gloeosporioides in avocado fruits. Mol. Plant-Microbe Interact. 7:326333.

22. Prusky, D., and Plumbley, R. A. 1992. Quiescent infection of Colletotrichum in tropical and subtropical fruits. Pages 289-307 in: Colletotrichum: Biology and Control. J. A. Baily and M. Jeger, eds. CAB International, Wallingford, U.K.

23. Prusky, D., Plumbley, R. A., and Kobiler, I. 1991. The relationship between antifungal diene levels and fungal inhibition during quiescent infection of unripe avocado fruits by Colletotrichum gloeosporioides. Plant Pathol. 40:45-52.

24. Redman, R. S., Ranson, J. C., and Rodriguez, R. J. 1999. Conversion of the pathogenic fungus Colletotrichum magna to nonpathogenic endophytic mutualist by gene disruption. Mol. Plant-Microbe Interact. 12:969-975.

25. Redman, S. R., and Rodriguez, J. R. 1994. Factors affecting the efficient transformation of Colletotrichum species. Exp. Mycol. 18:230-246.

26. Rodriguez, J. R. 1993. Polyphosphate present in DNA preparations from filamentous fungal species of Colletotrichum inhibits restriction endonucleases and other enzymes. Anal. Biochem. 209:1-9.

27. Sambrook, J., Fritsch, E. F., and Maniatis, T. A. 1989. Molecular Cloning: A Laboratory Manual. 2nd ed. Cold Spring Harbor Laboratory, Cold Spring Harbor, NY.

28. Schiestl, R. H., and Petes, T. D. 1991. Integration of DNA fragments by illegitimate recombination in Saccharomyces cerevisiae. Proc. Natl. Acad. Sci. USA 88:7585-7589.

29. Shi, Z., Christian, D., and Leung, H. 1995. Enhanced transformation in Magnaporthe grisea by restriction enzyme mediated integration of plasmid DNA. Am. Phytopathol. Soc. 85:329-333.

30. Tu, J. C. 1985. An improved Mathur's medium for growth, sporulation and germination of spores of Colletotrichum lindemuthianum. Microbiosis $44: 87-93$.

31. Wang, J., Holden, D. W., and Leong, S. A. 1988. Gene transfer system for the phytopathogenic fungus Ustilago maydis. Proc. Natl. Acad. Sci. USA 85:865-869.

32. Wilson, C. L., and Chalutz, E. 1989. Postharvest biological control of Penicillium rots of citrus with antagonistic yeast and bacteria. Sci. Hortic. 40:105-112.

33. Wisniewskii, M., Biles, C., Droby, S., McLaughlin, R., Wilson, C. L., and Chalutz, E. 1991. Mode of action of the postharvest biocontrol yeast Pichia guilliermondii. Vol. 1. Characterization of attachment to Botrytis cinerea. Physiol. Mol. Plant Pathol. 39:245-258.

34. Yakoby, N., Freeman, S., Dinoor, A., Keen, N. T., and Prusky, D. 2000. Expression of pectate lyase from Colletotrichum gloeosporioides in $C$. magna promotes pathogenicity. Mol. Plant-Microbe Interact. 13:887-891.

35. Yang, G., Rose, M. S., Turgeon, B. G., and Yoder, O. C. 1996. A polyketide synthase is required for fungal virulence and production of the polyketide T-toxin. Plant Physiol. 8:2139-2150. 